\title{
Electrochemical Glucose Sensors Enhanced by Methyl Viologen and Vertically Aligned Carbon Nanotube Channels
}

\author{
Benjamin J. Brownlee \\ Brigham Young University - Provo \\ Meisam Bahari \\ Brigham Young University - Provo \\ John N. Harb \\ Brigham Young University - Provo \\ Jonathan C. Claussen \\ lowa State University \\ Brian D. Iverson

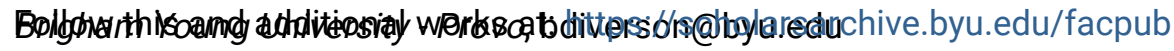 \\ Part of the Mechanical Engineering Commons
}

\section{Original Publication Citation}

Brownlee, B. J., Bahari, M., Harb, J. N., Claussen, J. C., and Iverson, B. D., 2018, "Electrochemical glucose sensors enhanced by methyl viologen and vertically aligned carbon nanotube channels," ACS Applied Materials and Interfaces, Vol. 10, pp. 28351-28360. DOI: 10.1021/acsami.8b08997

\section{BYU ScholarsArchive Citation}

Brownlee, Benjamin J.; Bahari, Meisam; Harb, John N.; Claussen, Jonathan C.; and Iverson, Brian D., "Electrochemical Glucose Sensors Enhanced by Methyl Viologen and Vertically Aligned Carbon Nanotube Channels" (2018). Faculty Publications. 5095.

https://scholarsarchive.byu.edu/facpub/5095

This Peer-Reviewed Article is brought to you for free and open access by BYU ScholarsArchive. It has been accepted for inclusion in Faculty Publications by an authorized administrator of BYU ScholarsArchive. For more information, please contact ellen_amatangelo@byu.edu. 


\title{
Electrochemical Glucose Sensors Enhanced by Methyl Viologen and Vertically Aligned Carbon Nanotube Channels
}

\author{
Benjamin J. Brownlee, ${ }^{\dagger}$ Meisam Bahari, ${ }^{\ddagger}$ John N. Harb, ${ }^{\ddagger}{ }^{\ddagger}$ Jonathan C. Claussen, ${ }^{\S}$ \\ and Brian D. Iverson* $* \dagger$
${ }^{\dagger}$ Department of Mechanical Engineering and ${ }^{\ddagger}$ Department of Chemical Engineering, Brigham Young University, Provo, Utah 84602, United States
${ }^{\S}$ Department of Mechanical Engineering, Iowa State University, Ames, Iowa 50011, United States
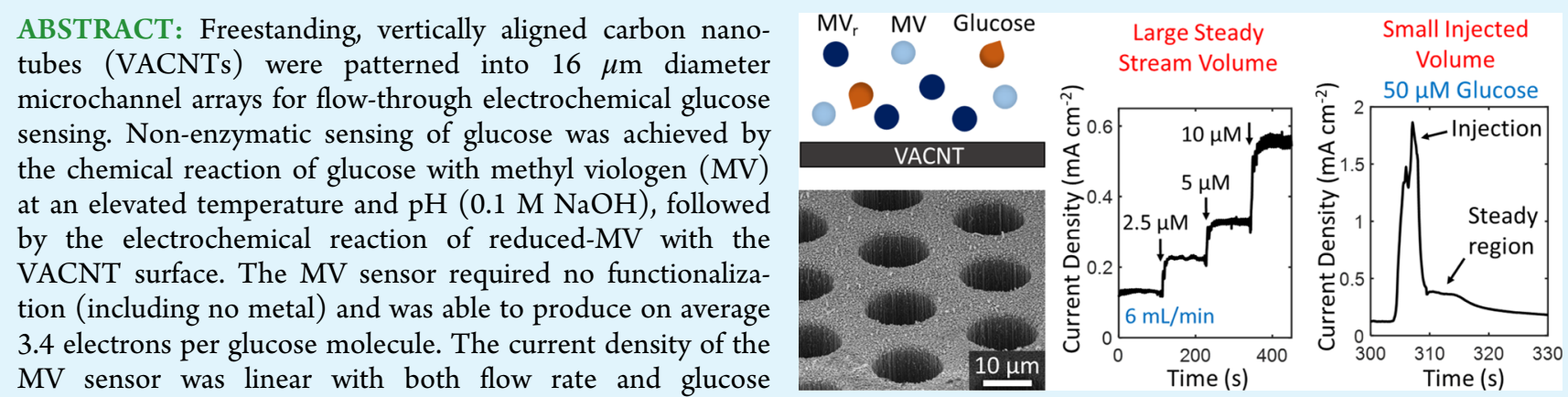

concentration. Challenges with interference chemicals were mitigated by operating at a low potential of $-0.2 \mathrm{~V}$ vs $\mathrm{Ag} / \mathrm{AgCl}$. As a comparison, enzymatic VACNT sensors with platinum nano-urchins were functionalized with glucose oxidase by covalent binding (1-ethyl-3-(-3-dimethylaminopropyl)carbodiimide/ $N$-hydroxysuccinimide) or by polymer entrapment [poly(3,4-ethylene-dioxythiophene)] and operated in phosphate buffered saline. With normalization by the overall cross-sectional area of the flow $\left(0.713 \mathrm{~cm}^{2}\right)$, the sensitivity of the MV, enzyme-insolution, and covalent sensors were 45.93, 18.77, and $1.815 \mathrm{~mA} \mathrm{~cm} \mathrm{mM}^{-1}$, respectively. Corresponding limits of detection were 100,194 , and $311 \mathrm{nM}$ glucose. The linear sensing ranges for the sensors were $250 \mathrm{nM}$ to $200 \mu \mathrm{M}$ glucose for the $\mathrm{MV}$ sensor, $500 \mathrm{nM}$ to $200 \mu \mathrm{M}$ glucose for the enzyme-in-solution sensor, and $1 \mu \mathrm{M}$ to $6 \mathrm{mM}$ glucose for the covalent sensor. The flow cell and sensor cross-sectional area were scaled down $\left(0.020 \mathrm{~cm}^{2}\right)$ to enable detection from $200 \mu \mathrm{L}$ of glucose with MV by flow injection analysis. The sensitivity of the small MV sensor was $5.002 \mathrm{~mA} \mathrm{~cm} \mathrm{mM}^{-1}$, with a limit of detection of $360 \mathrm{nM}$ glucose and a linear range up to at least $150 \mu \mathrm{M}$ glucose. The small MV sensor has the potential to measure glucose levels found in $200 \mu \mathrm{L}$ of saliva.

KEYWORDS: electrochemical sensor, glucose, methyl viologen, vertically aligned carbon nanotubes (VACNTs), microchannel, flow injection analysis (FIA)

\section{INTRODUCTION}

With recent advances in nanomaterials, many glucose sensors have been able to greatly lower their detection limits. Metal and metal oxide nanoparticles, ${ }^{1}$ along with carbon nanomaterials such as carbon nanotubes (CNTs), ${ }^{2-4}$ graphene, ${ }^{5-7}$ and graphene oxide, ${ }^{8}$ have been shown to be effective at increasing sensor sensitivity. ${ }^{9}$ CNTs are favorable for electrochemical sensing because of their high surface area, mechanical strength, and electrical conductivity. ${ }^{10}$ Many sensors incorporate randomly dispersed nanomaterials (including CNTs) that are cast on an electrode surface. ${ }^{11}$ This often requires the use of binders resulting in densely packed nanostructures with poor mechanical stability. ${ }^{12}$ Nanostructures grown from an electrode surface, such as nanorods, have been shown to have greater stability, while allowing for greater exposed surface area. ${ }^{13}$ In a similar fashion, vertically aligned carbon nanotubes (VACNTs) provide an ordered, preferential orientation of CNTs with a high surface-area-to-volume ratio enabling high sensitivity. Glucose sensors are often electrochemically based, which offers good repeatability, affordability, and ease of use as concentration levels can be quantified even in turbid solutions with a digital output. ${ }^{14}$

An additional means of improving sensitivity involves taking advantage of convection. Flow-through sensors improve the reaction-diffusion kinetics and consequently are more efficient at reacting the target analyte at the electrode surface than traditional bulk sensors. Highly efficient detection of hydrogen peroxide $\left(\mathrm{H}_{2} \mathrm{O}_{2}\right)$ with a flow-through VACNT electrode has been demonstrated in convective environments, ${ }^{15}$ but an investigation into the effectiveness of flow-through sensing for more complex analyte such as glucose is still needed. Flowthrough sensors also have the potential for flow injection

Received: May 30, 2018

Accepted: August 1, 2018

Published: August 1, 2018 
analysis (FIA), which enables use of much smaller sample volumes. $^{16}$

When glucose is not broken down by the body efficiently, the levels of glucose in the blood stream rise, with the potential for diabetes mellitus as a common resulting metabolic disorder. ${ }^{17}$ Over 400 million people have diabetes worldwide, ${ }^{18}$ with many health risks involved if diabetes is not properly diagnosed and treated. ${ }^{19}$ Thus, early and accessible diagnostics are important in reducing the negative side-effects of untreated diabetes. There has been much investigation in continuous glucose monitoring sensors ${ }^{20}$ and non-intrusive methods as alternatives to traditional blood-pricking methods. $^{21}$ Saliva is a more accessible bodily fluid and studies have shown that glucose levels in saliva can be directly correlated with the glucose levels in blood. ${ }^{22}$ However, the glucose concentration in saliva is significantly lower than that of blood, requiring a more sensitive glucose sensor to measure glucose levels accurately.

Glucose has also been investigated as a clean alternative energy source through biofuel cells, with recent advances focusing on improving performance with nanomaterials. ${ }^{23}$ Glucose-based biofuel cells are typically small-scale energy production devices and have been considered for applications such as self-powered medical devices. ${ }^{24,25}$ While fuel cells typically have electrolyte flowing between two electrodes, it has also been shown that glucose biofuel cells can operate in flowthrough conditions, with solution flowing through an entire biofuel cell. $^{26}$

Both glucose sensors and biofuel cells commonly use the enzyme glucose oxidase (GOx) to react with glucose. Biofuel cells typically use an electron-mediator, while glucose sensors often convert glucose into $\mathrm{H}_{2} \mathrm{O}_{2}$, which in turn reacts electrochemically at the electrode surface. Enzymatic glucose sensors are often functionalized with GOx on the surface, and it has been shown that the functionalization technique greatly impacts the sensitivity, selectivity, and longevity of such sensors. ${ }^{27}$ Primary methods of electrode functionalization include physical absorption, cross-linking, covalent bonding, bioaffinity bonding, and polymer entrapment. All enzymatic sensors are prone to enzyme detachment from the surface and to loss of enzyme activity over time; however, enzyme entrapment in conductive polymers has shown to be an effective method of functionalizing the GOx to maintain stability and functional form with minimal adverse steric effects. $^{28}$ Shi et al. have provided a comparison of functionalization methods for sol-gel encapsulation and glutaraldehyde cross-linking, ${ }^{29}$ but there lacks a comparison between different functionalization methods for high-aspectratio microstructures, where the functionalization needs to penetrate far beyond the easily accessible outer surface.

In the recent literature, there has been a trend in the development of non-enzymatic glucose sensors. ${ }^{30}$ Nonenzymatic sensors have risen in popularity because of their ease of manufacturing and because they do not have the same stability concerns common to enzymatic sensors. ${ }^{31}$ Moreover, non-enzymatic biosensors inherently exhibit long operational life, shelf-life, or stability as they do not contain biological components that typically denature within weeks of exposure to aqueous solutions. This stability offers the possibility of a reusable glucose sensor that would not degrade with time. However, non-enzymatic biosensors typically suffer from poor selectivity, especially to electroactive species such as ascorbic acid (AA), uric acid (UA), and acetaminophen (AP)- chemical species found endogenously in biological fluids such as blood.

Methyl viologen (MV) may enable a path to improving sensitivity and selectivity of non-enzymatic glucose biosensors. MV has previously been used in conjunction with GOx as an electron-mediator both in solution ${ }^{32}$ and immobilized on a sensor surface. ${ }^{33}$ However, recent studies have shown that MV can chemically react with glucose (non-enzymatically) at a sufficiently high temperature and $\mathrm{pH}$ for potential use in fuel cell applications. ${ }^{34}$ This same chemical reaction could also be used for glucose detection, such that the oxidation of reduced$\mathrm{MV}\left(\mathrm{MV}_{\mathrm{r}}\right)$ could be correlated with the concentration of glucose, something that has never been done previously in the literature.

Herein, we have manufactured a freestanding, VACNT electrode with $16 \mu \mathrm{m}$ diameter microchannels ( $\sim 350 \mu \mathrm{m}$ long) as a flow-through glucose sensor. A unique method of glucose detection involving a chemical reaction with MV was explored. $\mathrm{MV}$ was chemically reduced in the presence of glucose and was subsequently oxidized at the VACNT surface, requiring no additional surface functionalization (including no metal). Challenges with interference chemicals were mitigated by operating at a low potential of $-0.2 \mathrm{~V}$ vs $\mathrm{Ag} / \mathrm{AgCl}$. This MVbased VACNT sensor was compared to enzymatic VACNT electrodes functionalized by strategies typical for enzymatic glucose sensors. Unlike the MV sensor, the VACNTs of the enzymatic sensors were functionalized with $\mathrm{Pt}$ nano-urchins. GOx was incorporated into three different enzymatic VACNT sensors: GOx mixed into the solution, GOx covalently bound to the VACNTs, and GOx entrapped in a polymer on the CNTs. The electrochemical reaction of MV on the VACNT surface was able to produce more electrons per glucose molecule than is possible with GOx (an average of 3.4, compared to a maximum of 2). Current density was linear with flow rate for $\mathrm{MV}$ and GOx-in-solution sensing approaches. However, current density was not linear with flow rate when the chemical and electrochemical reactions both happened at the electrode surface, as was the case with the covalent and polymer VACNT sensors. The current density of each of the sensors was linear with glucose concentration, with the MV sensor producing the highest sensitivity and lowest limit of detection (LOD). FIA allows for a more practical application, where smaller analyte volumes can be tested by reducing the cross-sectional area of the VACNT electrode. Using MV with a small flow cell has the potential to measure glucose levels with $200 \mu \mathrm{L}$ of samples in the concentration range typical of saliva.

\section{METHODS}

2.1. VACNT Fabrication. VACNT fabrication methods were similar to previously published protocols. ${ }^{15,35}$ Summarizing, $50 \mathrm{~nm}$ of aluminum oxide $\left(\mathrm{Al}_{2} \mathrm{O}_{3}\right)$ was deposited onto a $100 \mathrm{~mm}$ silicon $(\mathrm{Si})$ wafer by e-beam evaporation. Photolithography was used to pattern positive photoresist (AZ3330) into an array of $16 \mu \mathrm{m}$ diameter circles that would eventually allow for the formation of defined channels. A thin $(7 \mathrm{~nm})$ film of iron $(\mathrm{Fe})$ was thermally evaporated onto the patterned photoresist, followed by sonication in $\mathrm{N}$-methyl-2pyrrolidone for at least $10 \mathrm{~min}$ for lift-off patterning of $\mathrm{Fe}$ (see schematic in Figure 1A). The patterned wafer was diced into $17 \mathrm{~mm}$ squares using a diamond-coated blade.

VACNTs were grown by chemical vapor deposition in a 1 in. diameter Lindberg/Blue $M$ tube furnace with flowing hydrogen $\left(\mathrm{H}_{2}\right.$, $311 \mathrm{sccm})$ and ethylene $\left(\mathrm{C}_{2} \mathrm{H}_{4}, 338 \mathrm{sccm}\right)$ at $750{ }^{\circ} \mathrm{C}$ for $6 \mathrm{~min}$. The temperature was then raised to $900{ }^{\circ} \mathrm{C}$ and the $\mathrm{H}_{2}$ flow rate was reduced to $190 \mathrm{sccm}$ to infiltrate (coat) the VACNTs with 


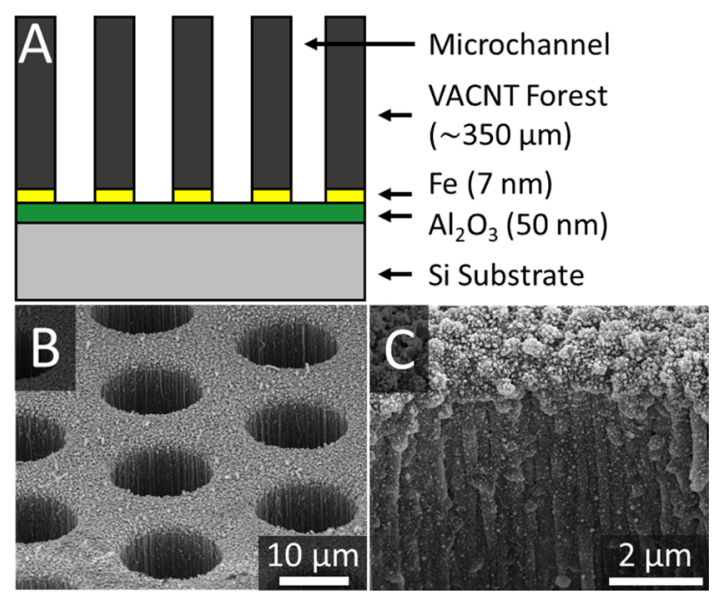

Figure 1. (A) Schematic of layers used to manufacture the VACNT sensor architecture (before self-release): $\mathrm{Si}, \mathrm{Al}_{2} \mathrm{O}_{3}, \mathrm{Fe}$, and VACNTs. (B) Scanning electron microscopy (SEM) image of array of VACNT microchannels with Pt. (C) SEM image near channel opening, showing Pt coverage on VACNTs.

amorphous carbon for $10 \mathrm{~min}\left(\mathrm{C}_{2} \mathrm{H}_{4}\right.$ flow rate was unchanged). This infiltration process strengthened the VACNT structure to create a mechanically sturdy, porous array of microchannels that self-released from the substrate (see geometry in Figure 1B). The resulting freestanding VACNT array (about $350 \mu \mathrm{m}$ thick) was placed in an oxygen plasma etch for $7 \mathrm{~min}$ ( $5 \mathrm{~min}$ on bottom; $2 \mathrm{~min}$ on top) in a Technics Planar Etch II machine (250 W, 300 mTorr).

2.2. Functionalization for Enzyme-Based Sensing. 2.2.1. Platinum. The VACNTs used for enzymatic sensing were functionalized with platinum nano-urchins (PNUs) as shown in Figure 1B,C. The PNUs were deposited in a static, electroless environment by the chemical reduction of a $3 \mathrm{mM}$ chloroplatinic acid hexahydrate solution (37.5\% Pt, Sigma-Aldrich 206083) similar to previous protocols. ${ }^{35-37}$ The VACNT array was held vertically in a Teflon stand for about $18 \mathrm{~h}$ in a solution containing chloroplatinic acid, 18 $\mathrm{mL}$ of ultrapure water, and $2 \mathrm{~mL}$ of formic acid $(88 \% \mathrm{HCOOH}$, Macron 2592-05). After the deposition, the PNU-VACNT array was thoroughly rinsed in water and placed on a hot plate to evaporate excess liquid before measuring the Pt mass. Note that no PNUs were deposited on sensors used with MV (see Figure 2A), whereas PNUs were the only functionalization used for sensors with GOx-in-stream (see Figure 2B).

2.2.2. Covalent (EDC/NHS) Binding. GOx from Aspergillus niger (GOx, type X-S, $100000-250000$ units/g, Sigma-Aldrich G7141) was covalently bonded to the PNU-VACNT array using 1-ethyl-3-(-3dimethylaminopropyl)carbodiimide (EDC, Sigma-Aldrich E7750) and N-hydroxysuccinimide (NHS, Sigma-Aldrich 130672) chemistry following approximately the conditions that were optimized by Wang et al. (see Figure $2 \mathrm{C}) .^{38}$ The PNU-VACNT array was incubated in 5 $\mathrm{mL}$ of $50 \mathrm{mM}$ EDC and $400 \mathrm{mM}$ NHS in $0.1 \mathrm{M} \mathrm{2-}(\mathrm{N}-$ morpholino)ethanesulfonic acid ( $\mathrm{pH} \mathrm{4.7,} \mathrm{Thermo} \mathrm{Scientific} \mathrm{28390)}$ for $90 \mathrm{~min}$ to allow the carboxyl groups on the VACNTs to react with
EDC and to form NHS esters in preparation for GOx coupling. The sample was then rinsed with ultrapure water and then placed in a 5 $\mathrm{mL}$ phosphate buffered saline (PBS, $\mathrm{pH} 7.4$ ) solution with $50 \mathrm{mg}$ of GOx $(10 \mathrm{mg} / \mathrm{mL})$. The EDC/NHS-PNU-VACNT array was incubated in the GOx mixture at $4{ }^{\circ} \mathrm{C}$ at least $16 \mathrm{~h}$. The GOxEDC/NHS-PNU-VACNT (hereafter, referred to as the EDC/NHS sensor) was then thoroughly rinsed and stored in PBS at $4{ }^{\circ} \mathrm{C}$.

2.2.3. Polymer (PEDOT) Entrapment. GOx was entrapped in the polymer poly(3,4-ethylene-dioxythiophene) (PEDOT) at the PNUVACNT surfaces following a procedure similar to that of Claussen et al. (see Figure 2D). ${ }^{7}$ First, 35 mg of poly(sodium 4-styrenesulfonate) (PSS, Sigma-Aldrich 243051) was stirred into $5 \mathrm{~mL}$ of ultrapure water. Then, $16 \mu \mathrm{L}$ of 3,4-ethylene-dioxythiophene (EDOT, SigmaAldrich 483028) was mixed into the PSS solution. Finally, $50 \mathrm{mg}$ of GOx $(10 \mathrm{mg} / \mathrm{mL})$ was added to the EDOT-PSS solution. The electropolymerization of EDOT to PEDOT was performed in a flow cell (see section 2.4 below) at a flow rate of $0.1 \mathrm{~mL} / \mathrm{min}$ with a multistep current $(0.5 \mathrm{~s}$ at $1 \mathrm{~mA}$ and $0.5 \mathrm{~s}$ at $0 \mathrm{~A})$ for 500 cycles. The resulting GOx-PEDOT-PSS-PNU-VACNT (hereafter, referred to as the PEDOT sensor) was thoroughly rinsed and stored in PBS at 4 ${ }^{\circ} \mathrm{C}$.

2.3. Amperometric Measurements and Environments. All experiments were performed in a flow-through electrochemical cell (see section 2.4) with a saturated $(\mathrm{KCl}) \mathrm{Ag} / \mathrm{AgCl}$ reference electrode, a Pt wire counter electrode, and a VACNT microchannel array as the working electrode. A CH Instruments (CHI) 660E potentiostat/ galvanostat was employed for all electrochemical testing. Before experiments were performed, a potential (see below for values) was applied to the VACNT electrode until a steady current density was obtained.

2.3.1. Glucose Oxidase. Glucose (dextrose, Sigma-Aldrich D9434) oxidation with GOx took place under a constant potential of $0.55 \mathrm{~V}$ relative to $\mathrm{Ag} / \mathrm{AgCl}$ in $\mathrm{PBS}(1 \times \mathrm{PBS}, \mathrm{pH} 7.4$, Fisher Scientific) at room temperature and typical air exposure. The two-part reaction converted glucose into hydrogen peroxide $\left(\mathrm{H}_{2} \mathrm{O}_{2}\right)$ as shown in eq 1 , and then, the $\mathrm{H}_{2} \mathrm{O}_{2}$ was oxidized at the PNU-VACNT surface to produce two electrons as shown by eq 2 (equilibrium potential of $0.204 \mathrm{~V}$ vs $\mathrm{Ag} / \mathrm{AgCl}$ at $\mathrm{pH} 7.4) .{ }^{39}$

$$
\begin{aligned}
& \text { D-glucose }+\mathrm{O}_{2}+\mathrm{H}_{2} \mathrm{O} \rightarrow \text { D-gluconic acid }+\mathrm{H}_{2} \mathrm{O}_{2} \\
& \mathrm{H}_{2} \mathrm{O}_{2} \rightarrow \mathrm{O}_{2}+2 \mathrm{H}^{+}+2 \mathrm{e}^{-}
\end{aligned}
$$

2.3.2. Methyl Viologen. For the non-enzymatic detection of glucose, methyl viologen dichloride hydrate (MV, 98\%, Fisher Scientific) was used to chemically react with glucose to produce $\mathrm{MV}_{\mathrm{r}}$. For this reaction to occur at relevant rates, it was required to increase both temperature and $\mathrm{pH},{ }^{34}$ with optimal conditions at $55^{\circ} \mathrm{C}$ (at a $60{ }^{\circ} \mathrm{C}$ set point) and $\mathrm{pH} 13$ (using $0.1 \mathrm{M} \mathrm{NaOH}$ ). In a basic electrolyte, glucose experiences an enolization process where glucose molecules are converted into endiolate anions, as shown in eq 3 (where D-glucose* represents the endiolate species). ${ }^{40,41}$ The endiolate species react with MV (the oxidized form of the catalyst), where $M V$ reduces to $M V_{r}$ (eq 4). Under this oxidation reaction, the endiolate species then convert into various products that depends on the oxidation extent of the glucose.

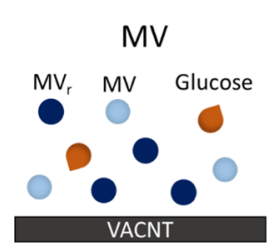

A

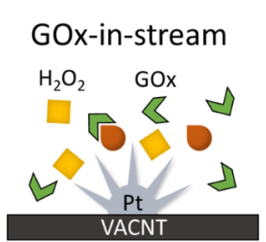

B

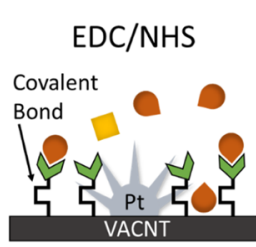

C

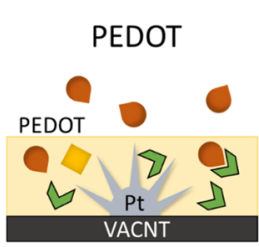

D

Figure 2. Various VACNT glucose sensor configurations. (A) Non-enzymatic MV sensor with no surface functionalization. (B) GOx-in-stream sensor, with Pt on the surface. (C) EDC/NHS sensor with GOx covalently bonded to the VACNTs. (D) PEDOT sensor with GOx entrapped in the polymer. 

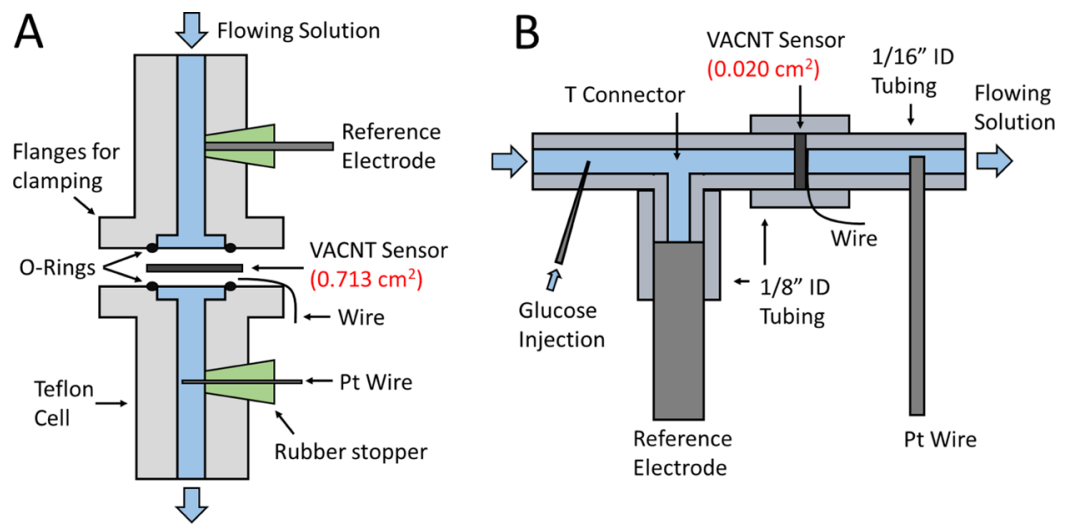

Figure 3. Schematic of (A) large and (B) small flow-through cells, where the chemical solution is forced through the VACNT microchannels. The small flow cell enables FIA of $200 \mu \mathrm{L}$ of glucose.
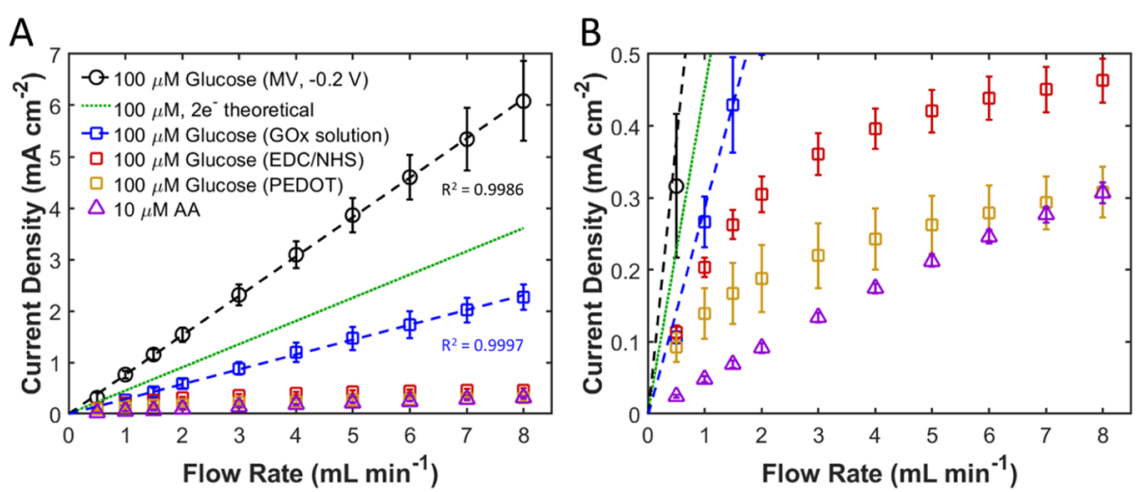

Figure 4. (A) Comparison of current density from $100 \mu \mathrm{M}$ glucose for different VACNT electrodes at various flow rates $(0.5-8 \mathrm{~mL} / \mathrm{min})$. The current densities from MV and GOx-in-stream sensors were both linear with flow rate, with the MV sensor collecting more than 2 electrons per glucose molecule. The MV sensor operated at $-0.2 \mathrm{~V}$ vs $\mathrm{Ag} / \mathrm{AgCl}$ in $0.1 \mathrm{M} \mathrm{NaOH}$, while the remainder of the sensors were tested at $0.55 \mathrm{~V}$ vs $\mathrm{Ag} /$ $\mathrm{AgCl}$ in $\mathrm{pH} 7.4 \mathrm{PBS}$. The current density from $\mathrm{AA}$ at $0.55 \mathrm{~V}$ vs Ag/ $\mathrm{AgCl}$ is also shown. (B) Close-up of low current density measurements, showing that the EDC/NHS and PEDOT sensors were nonlinear with flow rate. Note that error bars represent standard deviation from three repeat measurements.

$$
\begin{aligned}
& \text { D-glucose }+\mathrm{OH}^{-} \rightarrow \text { D-glucose* } \\
& \text { D-glucose* }+\mathrm{MV} \rightarrow \mathrm{MV}_{\mathrm{r}}+\text { products }
\end{aligned}
$$

The produced $M V_{r}$ is a free species in the electrolyte which is subsequently oxidized directly on the VACNT surface at a potential of $-0.2 \mathrm{~V}$ vs $\mathrm{Ag} / \mathrm{AgCl}$ without the presence of platinum or any other functionalization on the VACNT structure following eq 5 [standard potential of $-0.644 \mathrm{~V}$ vs $\mathrm{Ag} / \mathrm{AgCl}$, converted from saturated calomel electrode (SCE). ${ }^{42}$

$$
\mathrm{MV}_{\mathrm{r}} \rightarrow \mathrm{MV}+\mathrm{e}^{-}
$$

Note that MV in eq 5 represents oxidized-MV, returning to its original state before being reduced by glucose.

MV experiments were performed in an anaerobic glovebox to prevent oxidation of $\mathrm{MV}_{\mathrm{r}}$, which oxidizes readily in atmospheric conditions with oxygen. Glucose- $\mathrm{NaOH}$ solution in $15 \mathrm{~mL}$ test tubes (varying concentrations, including a control without glucose) was held in a water bath for about $10 \mathrm{~min}$, after which MV was added (1 $\mathrm{mM} \mathrm{MV}$ ) and allowed to react for $20 \mathrm{~min}$ before introducing the solution into the flow-through set up.

2.4. Flow Cell Configurations. The larger electrochemical flow cell is shown in Figure 3A, where the VACNT sensor was held between two, size-12 O-rings ( $3 / 8^{\prime \prime}$ i.d.) in a clamped Teflon flow cell. Forced mechanical contact between the VACNT electrode and a Nichrome wire allowed for a simple connection mechanism. The flow cell was oriented vertically, with the reference electrode upstream and the counter electrode downstream of the VACNT, each held in place by bored out rubber stoppers. A $60 \mathrm{~mL}$ syringe pulled solution through the cell from a reservoir using a Harvard Apparatus PHD Ultra syringe pump to control the flow rate. New premixed concentrations of glucose solution were added to the open reservoir as the previous solution emptied from the reservoir. At high glucose concentrations $(>500 \mu \mathrm{M})$, the syringe pump was operated in infuse mode instead of withdraw mode to allow bubbles to form at the electrode to escape (only relevant with GOx sensors as no bubbles formed from MV).

Figure 3B shows an application of the VACNT sensor at a much smaller scale, where glucose can be injected into the stream (FIA) instead of being premixed in the solution. A much smaller crosssection of VACNT electrode was positioned between two pieces of $1 /$ $16^{\prime \prime}$ i.d. (1/8" o.d.) poly(vinyl chloride) tubing and held together by $1 / 8^{\prime \prime}$ i.d. (3/16" o.d.) tubing. A T-connector was used to allow the reference electrode access to the solution, which was also held in place by $1 / 8^{\prime \prime}$ i.d. tubing. The solution was pushed (infused) through at a rate of $0.2 \mathrm{~mL} / \mathrm{min}$. A $200 \mu \mathrm{L}$ sample of glucose was manually injected upstream into the tubing over approximately $4 \mathrm{~s}(\sim 3 \mathrm{~mL} /$ $\min )$.

\section{RESULTS AND DISCUSSION}

3.1. Characterization. VACNT heights (electrode thicknesses) were measured to be $351 \pm 27 \mu \mathrm{m}$. With a nominal channel diameter of $16 \mu \mathrm{m}$, the channel length-to-diameter ratio was about 22 . The nominal void ratio of each electrode was 0.41 . VACNTs coated with amorphous carbon have been shown to have a high number of surface defects that are 
favorable for increasing charge transfer, as previously shown by Raman spectroscopy. ${ }^{43}$

For the enzymatic sensors, the mass of the deposited Pt was measured to be $4.46 \pm 0.70 \mathrm{mg}(14.7 \pm 2.3 \%$ of sensor by weight). More detailed characterization of $\mathrm{Pt}$ deposited in a similar manner can be found by others, including analysis by transmission electron microscopy ${ }^{35}$ and X-ray diffraction. ${ }^{44}$

3.2. MV Wait Time. For the chemical reaction of glucose with MV, a maximum $\mathrm{pH}$ of 12 is recommended by Watt because MV becomes unstable at high $\mathrm{pH} .{ }^{34}$ However, it was found that at relatively low MV concentrations ( $1 \mathrm{mM}), \mathrm{MV}$ could be used in a $\mathrm{pH} 13$ solution $(0.1 \mathrm{M} \mathrm{NaOH})$ because the rate of MV decomposition was negligible compared to the glucose-MV reaction. Thus, a $\mathrm{pH} 13$ solution was chosen to provide faster reaction rates of glucose and reduce the waiting time. To determine the optimal waiting time for the reaction, the current was measured in the large flow cell in $10 \mathrm{~min}$ intervals (data not shown). A maximum current was obtained at $30 \mathrm{~min}$, with $82 \%$ of the maximum at $10 \mathrm{~min}$ and $97 \%$ of the maximum at $20 \mathrm{~min}$. Longer times (40 and $50 \mathrm{~min}$ ) resulted in a slight decrease in the measured current. Thus, a 20 min wait time was chosen for all subsequent experiments.

3.3. Flow Rate. Flow rate greatly influences the sensitivity of flow sensors and can provide linearly varying current with flow rate. ${ }^{15}$ Figure 4 shows the measured current density for $100 \mu \mathrm{M}$ glucose at different volumetric flow rates $(0.5-8 \mathrm{~mL} /$ $\mathrm{min}$; average velocities: $0.283-4.53 \mathrm{~mm} / \mathrm{s}$ ) for each of the glucose sensors (MV, GOx-in-stream, EDC/NHS, and PEDOT; see Figure 2) in the large flow cell. A concentration of $100 \mu \mathrm{M}$ glucose was chosen to mimic a typical glucose concentration found in saliva and is representative of an accessible bodily fluid with a lower concentration. The current was normalized by the frontal surface area, as defined by the $\mathrm{O}$ rings $\left(0.713 \mathrm{~cm}^{2}\right)$.

Figure $4 \mathrm{~A}$ shows that the current density was the largest and most linear with flow rate when the glucose reaction occurred upstream of the VACNT electrode, as was the case with both GOx and MV in solution. The green dashed line represents the current density that would be obtained for $100 \mu \mathrm{M}$ glucose (at the given flow rate) if each glucose molecule produced two electrons. This becomes the theoretical maximum for GOx reactions if each glucose molecule was converted into $\mathrm{H}_{2} \mathrm{O}_{2}$ and then each $\mathrm{H}_{2} \mathrm{O}_{2}$ molecule reacted at the surface (see eqs 1 and 2). However, when the GOx was in the stream, a reaction efficiency of glucose to $\mathrm{H}_{2} \mathrm{O}_{2}$ was observed, as the current density was only about $64 \%$ the theoretical values. On the other hand, the MV reaction produced a significantly higher current density, at approximately 2.65 times the current density produced with GOx in stream, resulting in an average of 3.4 electrons per glucose molecule. This is possible because it is not $\mathrm{H}_{2} \mathrm{O}_{2}$, but $\mathrm{MV}_{\mathrm{r}}$, that is oxidized at the electrode surface (see eq 5). Tests were repeated for three separate VACNT sensors with an average standard deviation relative to the mean of $11.9 \%$. It should be noted that the lowest flow rate gave a much higher relative standard deviation of $31.5 \%$ and was likely due to experimental error.

When the chemical reaction was moved to the electrode by functionalizing the VACNTs with GOx, a nonlinear trend with flow rate was observed (see Figure 4B). At the lowest flow rate tested $(0.5 \mathrm{~mL} / \mathrm{min})$, the current density of each of the GOx sensors was very similar, but the current densities of the functionalized sensors begin to asymptote as flow rate increases. This suggests that the time component to the two- part reaction of glucose with $\mathrm{GOx}$ and $\mathrm{H}_{2} \mathrm{O}_{2}$ with the PNUVACNT surface becomes significant at high flow rates. For example, at $0.5 \mathrm{~mL} / \mathrm{min}$ there would be on average $1.24 \mathrm{~s}$ to complete the chemical and electrochemical reactions within the VACNT array, but only $0.08 \mathrm{~s}$ at $8 \mathrm{~mL} / \mathrm{min}$. When the chemical reaction takes place before reaching the electrode, only the electrochemical portion needs to take place during this time. Although both the EDC/NHS and PEDOT sensors follow the same trend, it can also be seen in Figure 4B that the EDC/NHS sensor exhibited higher current densities at higher flow rates (about 1.5 times larger at $8 \mathrm{~mL} / \mathrm{min}$ ). The lower current from the PEDOT sensor could be caused from less coverage of GOx as a result of the polymer functionalization or because the polymer layer acts as a diffusion barrier between the VACNT surface and the solution. It is also possible that variations in PEDOT coverage and VACNT channel length caused the PEDOT sensor to have the largest average standard deviation relative to the mean at $18.8 \%$.

Flow rates for subsequent concentration tests were chosen to yield large current densities while still maintaining reasonable solution volumes. For GOx functionalized on the VACNTs, it is most efficient to be below $3 \mathrm{~mL} / \mathrm{min}$ at a concentration of $100 \mu \mathrm{M}$ because current does not increase significantly with flow above this point. A flow rate of $1 \mathrm{~mL} /$ min was chosen because the EDC/NHS current density was still close to the GOX-in-stream current density at this point and for reasons discussed in the following section on selectivity (see section 3.4). For the in-solution sensors, the selection of flow rate is slightly arbitrary as sensitivity will continue to increase with increasing flow rate. To maintain reasonable solution volumes, a flow rate of $6 \mathrm{~mL} / \mathrm{min}$ was chosen.

3.4. Selectivity. 3.4.1. Enzyme Sensors. Selectivity of glucose against interfering species is important for the accurate measurement of glucose concentrations. Also shown in Figure 4 is current density with flow rate for $10 \mu \mathrm{M}$ of AA (Fisher Scientific) at a potential of $0.55 \mathrm{~V}$ vs $\mathrm{Ag} / \mathrm{AgCl}$ (same as $\mathrm{GOx}$ tests), as tested with each of the GOx sensors (Pt only, EDC/ NHS, and PEDOT). The current density from this interfering species was rather large because AA oxidizes readily at this potential. ${ }^{45}$ This was especially significant for the low current densities of EDC/NHS and PEDOT sensors at high flow rates, which is the main reason to operate the functionalized sensors at a low flow rate $(1 \mathrm{~mL} / \mathrm{min})$. GOx-in-stream had the least impact, with the $10 \mu \mathrm{M}$ AA giving a current density about $15 \%$ of the $100 \mu \mathrm{M}$ glucose current density (minimal dependence on flow rate). At lower potentials, it is possible to minimize the effects of interfering species and measure the change in the $\mathrm{O}_{2}$ reduction current. ${ }^{45}$ However, at low potentials the PNUVACNTs produced a very large negative current from the reduction of oxygen, making it unreasonable to operate at low potentials in the presence of oxygen (oxygen is required for the GOx reaction).

It has previously been shown that a polymer layer such as PEDOT can help reduce the impact from interfering species. However, the current density was nearly identical with and without the PEDOT layer on the PNU-VACNT electrodes, as the small standard deviation in Figure $4 \mathrm{~B}$ includes both PEDOT and non-PEDOT samples. It is possible that the large surface area and high-aspect-ratio VACNT channels were not completely coated with the polymer, and the resulting electrode was thus able to oxidize the interfering species at the same rate as the sensors with PEDOT. 
3.4.2. MV Sensor. With MV, there was more flexibility in the operating potential of the sensor because tests were performed in an oxygen-free environment (avoiding the current from oxygen reduction while preventing the oxidation of $\left(\mathrm{MV}_{\mathrm{r}}\right.$ ) and because the standard equilibrium potential of $\mathrm{MV}$ is very low $\left(-0.644 \mathrm{vs} \mathrm{Ag} / \mathrm{AgCl}\right.$, converted from $\left.\mathrm{SCE}^{42}\right)$. It was observed that a significant current was produced by interfering species on the VACNT electrode at potentials above about $-0.2 \mathrm{~V}$ vs $\mathrm{Ag} / \mathrm{AgCl}$, below which the current from the interfering species was significantly lower (data not shown). Thus, a potential of $-0.2 \mathrm{~V}$ vs $\mathrm{Ag} / \mathrm{AgCl}$ was chosen for all experiments with $\mathrm{MV}$.

Figure 5 shows the impact of interfering species on the current density of $100 \mu \mathrm{M}$ glucose with $1 \mathrm{mM}$ MV. The initial

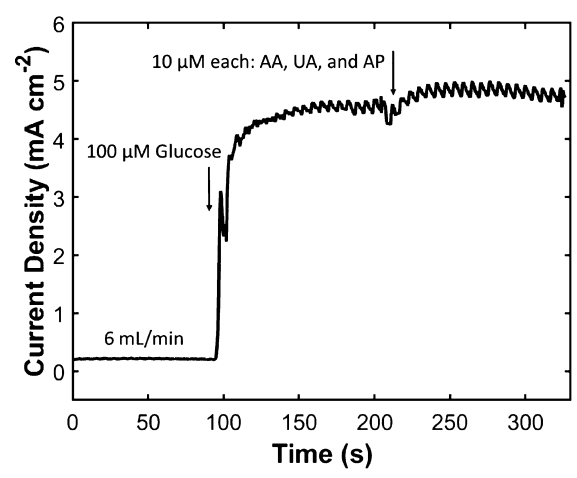

Figure 5. Current density with time for $100 \mu \mathrm{M}$ glucose and $1 \mathrm{mM}$ $\mathrm{MV}$ in $0.1 \mathrm{M} \mathrm{NaOH}$ flowing at $6 \mathrm{~mL} / \mathrm{min}$ and potential of $-0.2 \mathrm{~V}$ vs $\mathrm{Ag} / \mathrm{AgCl}$, followed by an upstream addition of $10 \mu \mathrm{M}$ of each of the following common interfering species: AA, UA, and AP. A 6\% increase in current was observed by the addition of interfering species with the glucose.

baseline is from heated $0.1 \mathrm{M} \mathrm{NaOH}$ and $1 \mathrm{mM} \mathrm{MV}$ flowing at $6 \mathrm{~mL} / \mathrm{min}$, followed by the upstream addition of heated $\mathrm{NaOH}$ with $100 \mu \mathrm{M}$ glucose and $1 \mathrm{mM} \mathrm{MV}$ at $\sim 100 \mathrm{~s}$. As this upstream solution was depleted, a comparable mixture was added to the upstream reservoir at $\sim 210 \mathrm{~s}$, now with several interfering chemicals present $[\mathrm{NaOH}$ heated with $100 \mu \mathrm{M}$ glucose, $10 \mu \mathrm{M} \mathrm{AA}, 10 \mu \mathrm{M}$ UA (Sigma-Aldrich U2625), 10 $\mu \mathrm{M}$ AP (Sigma-Aldrich A5000), and $1 \mathrm{mM} \mathrm{MV]}$. In this manner, the ability to detect glucose in the presence of the interfering chemicals was demonstrated. There was an observed increase in current density of about $6 \%$ from the three interfering species combined, likely caused by a slight reaction with MV. It should be noted that a small oscillation in the measured current was observed after the addition of glucose, as can be seen in Figure 5. The oscillations corresponded to the stepping of the syringe pump, a phenomenon previously observed in the signal for $\mathrm{H}_{2} \mathrm{O}_{2}$ detection. $^{15}$

3.5. Sensitivity, LOD, and Linear Sensing Range. The current density with time at lower concentrations of glucose (2.5-10 $\mu \mathrm{M})$ with $\mathrm{MV}$ is shown in Figure 6. The baseline is heated $\mathrm{NaOH}$ and $1 \mathrm{mM} \mathrm{MV}$ flowing at $6 \mathrm{~mL} / \mathrm{min}$, followed by the upstream additions of heated $\mathrm{NaOH}$ with glucose and 1 $\mathrm{mM}$ MV. At these low concentrations, there is still a distinct increase in current with the addition of glucose and a linear relationship between current density and glucose concentration is apparent.

Figure 7 shows the current density at various glucose concentrations for MV, GOx-in-solution, and EDC/NHS sensors. The PEDOT sensor was not included in the

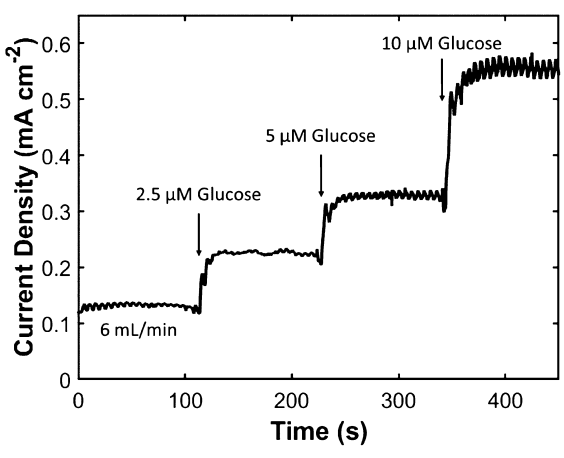

Figure 6. Current density with time for low glucose concentrations $(2.5,5$, and $10 \mu \mathrm{M})$ with $1 \mathrm{mM} \mathrm{MV}$ in $0.1 \mathrm{M} \mathrm{NaOH}$ at a flow rate of $6 \mathrm{~mL} / \mathrm{min}$ and potential of $-0.2 \mathrm{~V}$ vs $\mathrm{Ag} / \mathrm{AgCl}$.

concentration experiments because it showed no advantage over the EDC/NHS sensor from the flow rate experiments in section 3.3. In Figure 7A, the full linear range of the EDC/ NHS sensor is shown to be much larger than the other two sensors, up to about $6 \mathrm{mM}$ glucose. The MV and GOx-insolution sensors both reach their linear limit at about $200 \mu \mathrm{M}$ glucose. It is likely that the EDC/NHS electrode had a much larger linear range because it was operating at a much lower flow rate. Thus, it seems that the flow rate of the sensor could potentially be modified to target different concentration ranges with a linear response.

Figure $7 \mathrm{~B}$ shows the linear range for the MV and GOx-insolution sensors. It can be seen that each sensor is linear below $200 \mu \mathrm{M}$ glucose, with MV having the largest slope and thus the highest sensitivity at $45.93 \mathrm{~mA} \mathrm{mM} \mathrm{mm}^{-1}$ (based on the projected frontal area of $0.713 \mathrm{~cm}^{2}$ ). The LOD of each sensor was calculated from the sensitivity (based on 3 times the standard deviation of the baseline), with the observed lowest linear sensing region being slightly higher than the LOD. The MV sensor had the lowest LOD at $100 \mathrm{nM}$ glucose and was linear down to a concentration of $250 \mathrm{nM}$. Table 1 summarizes the measured performance of each VACNT sensor, including the sensitivity, LOD, and linear range. The low limits of detection and high sensitivities for the VACNT sensors shown in Table 1 are comparable with the best glucose sensors in the literature, with glucose sensors typically ranging from 5 to $100,000 \mathrm{nM}$ glucose LOD and sensitivities of $0.001-12 \mathrm{~mA}$ $\mathrm{mM}^{-1} \mathrm{~cm}^{-2}$. $, 14,28,46$ The large sensitivity of the VACNT sensors comes from high current per geometric cross-sectional area and does not include the surface area associated with microchannel length. It is interesting to note that although the sensitivity of the EDC/NHS sensor was much lower, the background noise was nearly proportionally smaller, such that the calculated LOD was still very similar to that of the other sensors. With GOx in solution, the background noise was significantly higher than that for PBS alone. Although the EDC/NHS sensor operated at a slower flow rate of $1 \mathrm{~mL} / \mathrm{min}$, it would have only marginally increased sensitivity if operated at $6 \mathrm{~mL} / \mathrm{min}$, as noted in section 3.3 .

3.6. Small Volume MV Sensor. A smaller flow cell (see Figure $3 \mathrm{~B}$ ) was used to demonstrate glucose detection with much smaller volumes $(200 \mu \mathrm{L})$ via FIA. The cross-sectional area was reduced by 36 times, giving an area of only $0.020 \mathrm{~cm}^{2}$ (compared to $0.713 \mathrm{~cm}^{2}$ ). A flow rate of $0.2 \mathrm{~mL} / \mathrm{min}$ was chosen, giving an average velocity of $4.08 \mathrm{~mm} / \mathrm{s}$. This velocity through the smaller sensor was comparable to that for the larger flow cell (equivalent to a large cell flow rate of $7.2 \mathrm{~mL} /$ 

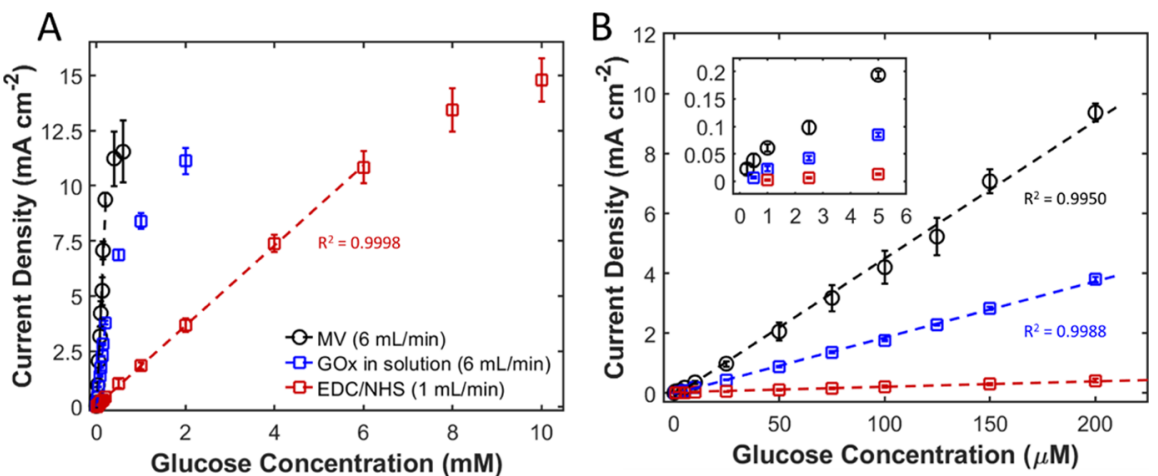

Figure 7. Measured current density at different glucose concentrations flowing at $1 \mathrm{~mL} / \mathrm{min}$ for EDC/NHS sensors and $6 \mathrm{~mL} / \mathrm{min}$ for MV and GOx-in-solution. The MV sensor operated at $-0.2 \mathrm{~V}$ in $0.1 \mathrm{M} \mathrm{NaOH}$, while GOx-in-solution and EDC/NHS sensors were tested at $0.55 \mathrm{~V}$ in $\mathrm{pH}$ 7.4 PBS. (A) Full linear range of EDC/NHS sensor is shown to be much larger than the linear range of GOx-in-solution and MV. (B) Current density for lower glucose concentrations, where all of the sensors are linear and MV has the highest current density for any given concentration. Inset: Linear sensing range as low as $0.25 \mu \mathrm{M}$. Note that error bars represent standard deviation from three repeat measurements.

\section{Table 1. Summary of Various VACNT Sensor Conditions and Measured Results in This Work}

\begin{tabular}{lccccc}
\multicolumn{1}{c}{ sensor } & potential $^{a}[\mathrm{~V}(\mathrm{Ag} / \mathrm{AgCl})]$ & flow rate $^{b}(\mathrm{~mL} / \mathrm{min})$ & sensitivity $^{c}\left(\mathrm{~mA} \mathrm{mM}^{-1} \mathrm{~cm}^{-2}\right)$ & LOD (nM) & linear range $(\mu \mathrm{M})$ \\
MV & -0.2 & 6 & 45.93 & 100 & $0.25-200$ \\
GOx-in-solution & 0.55 & 6 & 18.77 & 194 & $0.5-200$ \\
EDC/NHS & 0.55 & 1 & 1.815 & 311 & $1-6000$ \\
small MV & -0.2 & 0.2 & 5.002 & 360 & $<50$ to $>150^{d}$
\end{tabular}

${ }^{a}$ Chosen to produce high glucose signal while reducing signal from interfering species (see section 3.4$) .{ }^{b}$ Selected based on linearity and solution volume limitations as noted in section 3.3. ${ }^{c}$ Based on the projected frontal area of $0.713 \mathrm{~cm}^{2}$ (or $0.020 \mathrm{~cm}^{2}$ for small MV sensor). ${ }^{d}$ Linearity beyond this range was not explored.
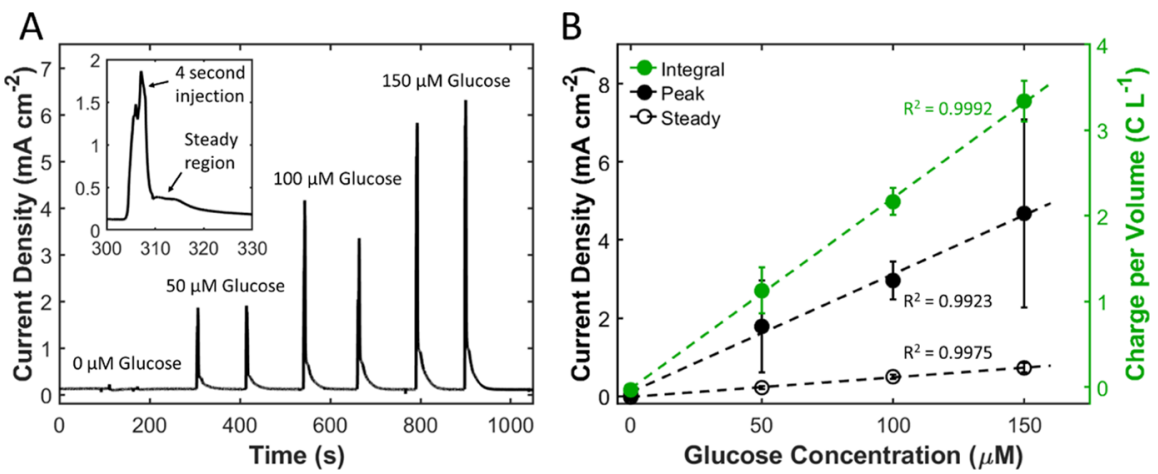

Figure 8. Small volume flow cell with $200 \mu \mathrm{L}$ injections of glucose $(0,50,100$, and $150 \mu \mathrm{M})$ and $1 \mathrm{mM} \mathrm{MV}$ flowing at $0.2 \mathrm{~mL} / \mathrm{min}$ and operating at $-0.2 \mathrm{~V}$ in $0.1 \mathrm{M} \mathrm{NaOH}$. (A) Current density from two injections of each concentration as a function of time. Inset: Zoomed view of $50 \mu \mathrm{M}$ injection, showing the peak caused by injection and a steady region before reducing to baseline current. (B) Methods used to detect glucose concentration including integration of current from injected glucose (normalized by injection volume), peak current density during injection, and steady current density just after injection. Each method is linear with concentration with the peak current density measurements exhibiting the largest standard deviation. Note that error bars represent standard deviation from the average of two tests for three repeat devices.

min). However, during glucose injection the velocity increased as the $200 \mu \mathrm{L}$ sample was injected over about $4 \mathrm{~s}$ (about $3 \mathrm{~mL} /$ min). The overall flow rate through the small sensor would then be $\sim 3.2 \mathrm{~mL} / \mathrm{min}$, suggesting that the solution concentration would be approximately $95 \%$ of the injected glucose concentration.

Figure $8 \mathrm{~A}$ shows the current density with time during the injection of different glucose concentrations $(0,50,100$, and $150 \mu \mathrm{M})$ and $1 \mathrm{mM}$ MV. The conditions were the same used with MV in the large flow cell: a 20 min wait time in $\mathrm{pH} 13$ $(0.1 \mathrm{M}) \mathrm{NaOH}$, with the VACNT electrode at a potential of $-0.2 \mathrm{~V}$. Two injections are shown for each concentration, with a close up of a single injection shown in the figure inset. There was a high current density measured during the glucose injection period (about $4 \mathrm{~s}$ ). After the injection, there was a steady region with a high glucose concentration at the original flow rate $(0.2 \mathrm{~mL} / \mathrm{min})$ before the current density reduced to the baseline current.

With this FIA, there are three different values that can be used to correlate with glucose concentration: (1) integration of the current to obtain total charge (normalized by the injection volume), (2) measured peak current density during injection, and (3) measured steady current density after the injection. Figure $8 \mathrm{~B}$ shows that each of these measurement techniques was linear with glucose concentration. However, a larger standard deviation of peak current density was observed (44.6\% average standard deviation relative to the mean), compared to the steady region current density (15.5\%). The 
large standard deviation of the peak current density was likely due to manual control of the injection rate, where the rate of injection greatly influenced the peak current densities.

Although the current-integration method is a valid calculation method, by using the current density measured in the steady region it was possible to determine a sensitivity and LOD that could be compared with the large flow cell. The sensitivity from the curve fit slope was determined to be 5.002 $\mathrm{mA} \mathrm{cm}{ }^{-2} \mathrm{mM}^{-1}$, which is about 9 times smaller than the sensitivity of the large flow cell. Although a larger sensitivity could be obtained using the peak current density, the measured signal was much more variable than the steady current density, as noted by the large error bars in Figure 8B.

With a smaller sensor also came much smaller background noise, which resulted in a calculated LOD of $360 \mathrm{nM}$ glucose. Thus, although the sensitivity was less than the large MV sensor, the smaller background noise helped give a comparable LOD. The full linear range was not investigated for the smaller sensor, but experiments demonstrate that the measurement was linear with concentration up to at least $150 \mu \mathrm{M}$ glucose. Within this concentration range and with as little as $200 \mu \mathrm{L}$ (or potentially less), the MV sensor has the potential to measure the glucose levels found in saliva. ${ }^{22}$

Table 1 reports the measured performance of the small sensor as compared to the other sensors in this work.

3.7. Advantages and Disadvantages of $M V$ for Glucose Sensing. MV has been shown to be a promising agent for enhancing glucose detection. Because the chemical reaction does not involve a pathway with $\mathrm{H}_{2} \mathrm{O}_{2}$, it is possible to detect more than 2 electrons per glucose molecule. This led to a very high sensitivity with a low LOD for both the large bulk experiments and for the small volume FIA experiments. Also, no additional functionalization of the sensor was necessary, as the electrode consisted of only carbon (VACNTs with added carbon from the infiltration process). This means that no metal was needed and also no enzyme was necessary, avoiding typical problems of enzymatic sensors, such as signal decay in time. The low working potential also allowed for minimizing the effect of interfering species.

The advantages of using MV come at a potential cost, as the MV sensor exhibits a few key restrictions when compared to GOx-based sensors. The temperature of the solution was elevated to $55{ }^{\circ} \mathrm{C}$ in order to facilitate the reaction of MV with glucose and was allowed to proceed for $20 \mathrm{~min}$ in an oxygenfree environment before measuring the current. The solution was also at $\mathrm{pH} 13$, likely requiring an increase in solution $\mathrm{pH}$, similar to many other non-enzymatic sensors. While these conditions may be challenging to implement and are limited to in vitro applications, the idea of utilizing an amplification chemical to react with glucose is an intriguing prospect.

\section{CONCLUSIONS}

This work has shown the effectiveness of using MV as the reacting agent for glucose detection. When combined with the VACNT electrode, the measured current density from the non-enzymatic MV reaction was very high (with a sensitivity of $45.93 \mathrm{~mA} \mathrm{mM}^{-1} \mathrm{~cm}^{-2}$ and a LOD of $100 \mathrm{nM}$ ). These high current densities were linear with both flow rate and glucose concentration in the $0.25-200 \mu \mathrm{M}$ range, and the effect from common interfering species was minimal at the low working voltage of $-0.2 \mathrm{~V}$ vs $\mathrm{Ag} / \mathrm{AgCl}$. Future work will involve investigating the interference from carbohydrates other than glucose. MV-based glucose sensing is potentially limited in self- glucose monitoring applications because of the chemical reaction of glucose with $\mathrm{MV}$ at an elevated temperature in an oxygen-free environment for several minutes before passing though the sensing electrode.

With surface-based, enzymatic GOx reactions, the measured current density leveled off at lower flow rates than for sensors that allowed the chemical reaction to take place in solution. For convective-enhanced sensor technologies, the additional requirement of having all of the chemical reactions taking place at the sensor surface introduces an additional limitation in utilizing flow rate to increase sensor sensitivity. Furthermore, measured current densities with MV were higher than theoretically possible with enzymatic GOx reactions, with a release of 3.4 electrons per glucose molecule on average. The additional electrons made available with MV in this flowing configuration may also be useful in increasing power output of glucose-based biofuel cells.

The MV sensor was scaled down in size to enable the detection of glucose in small volumes of only $200 \mu \mathrm{L}$. The small sensor had a high-enough sensitivity to potentially measure glucose levels found in saliva, with testing in real saliva samples as an area for future investigation. The small VACNT configuration could also be applied to enzymatic sensors, with potential future work including the exploration of injectionbased, small volume sensing with VACNT electrodes to enhance enzymatic sensing.

\section{AUTHOR INFORMATION}

\section{Corresponding Author}

*E-mail: bdiverson@byu.edu.

ORCID

John N. Harb: 0000-0002-4258-859X

Jonathan C. Claussen: 0000-0001-7065-1077

Brian D. Iverson: 0000-0002-4592-3728

\section{Notes}

The authors declare no competing financial interest.

\section{ACKNOWLEDGMENTS}

The authors gratefully acknowledge support from the Department of Mechanical Engineering and College of Engineering and Technology at Brigham Young University.

\section{REFERENCES}

(1) Sattayasamitsathit, S.; Gu, Y.; Kaufmann, K.; Jia, W.; Xiao, X.; Rodriguez, M.; Minteer, S.; Cha, J.; Burckel, D. B.; Wang, C.; Polsky, R.; Wang, J. Highly Ordered Multilayered 3D Graphene Decorated with Metal Nanoparticles. J. Mater. Chem. A 2013, 1, 1639-1645.

(2) Bandodkar, A. J.; Jeerapan, I.; You, J.-M.; Nuñez-Flores, R.; Wang, J. Highly Stretchable Fully-Printed CNT-Based Electrochemical Sensors and Biofuel Cells: Combining Intrinsic and Design-Induced Stretchability. Nano Lett. 2016, 16, 721-727.

(3) Gupta, S.; Murthy, C. N.; Prabha, C. R. Recent Advances in Carbon Nanotube Based Electrochemical Biosensors. Int. J. Biol. Macromol. 2018, 108, 687-703.

(4) Claussen, J. C.; Franklin, A. D.; ul Haque, A.; Porterfield, D. M.; Fisher, T. S. Electrochemical Biosensor of Nanocube-Augmented Carbon Nanotube Networks. ACS Nano 2009, 3, 37-44.

(5) Koushanpour, A.; Guz, N.; Gamella, M.; Katz, E. GrapheneFunctionalized 3D-Carbon Fiber Electrodes - Preparation and Electrochemical Characterization. Electroanalysis 2016, 28, 19431946.

(6) Lawal, A. T. Progress in Utilisation of Graphene for Electrochemical Biosensors. Biosens. Bioelectron. 2018, 106, 149-178. 
(7) Claussen, J. C.; Kumar, A.; Jaroch, D. B.; Khawaja, M. H.; Hibbard, A. B.; Porterfield, D. M.; Fisher, T. S. Nanostructuring Platinum Nanoparticles on Multilayered Graphene Petal Nanosheets for Electrochemical Biosensing. Adv. Funct. Mater. 2012, 22, 33993405.

(8) Bollella, P.; Fusco, G.; Tortolini, C.; Sanzò, G.; Favero, G.; Gorton, L.; Antiochia, R. Beyond Graphene: Electrochemical Sensors and Biosensors for Biomarkers Detection. Biosens. Bioelectron. 2017, $89,152-166$.

(9) Dhara, K.; Mahapatra, D. R. Electrochemical Nonenzymatic Sensing of Glucose Using Advanced Nanomaterials. Microchim. Acta 2018, 185, 49.

(10) Tsentalovich, D. E.; Headrick, R. J.; Mirri, F.; Hao, J.; Behabtu, N.; Young, C. C.; Pasquali, M. Influence of Carbon Nanotube Characteristics on Macroscopic Fiber Properties. ACS Appl. Mater. Interfaces 2017, 9, 36189-36198.

(11) Kumar, S.; Rani, R.; Dilbaghi, N.; Tankeshwar, K.; Kim, K.-H. Carbon Nanotubes: A Novel Material for Multifaceted Applications in Human Healthcare. Chem. Soc. Rev. 2017, 46, 158-196.

(12) Ahmad, R.; Ahn, M.-S.; Hahn, Y.-B. A Highly Sensitive Nonenzymatic Sensor Based on Fe2 O3 Nanoparticle Coated ZnO Nanorods for Electrochemical Detection of Nitrite. Adv. Mater. Interfaces 2017, 4, 1700691.

(13) Ahmad, R.; Tripathy, N.; Ahn, M.-S.; Hahn, Y.-B. Solution Process Synthesis of High Aspect Ratio ZnO Nanorods on Electrode Surface for Sensitive Electrochemical Detection of Uric Acid. Sci. Rep. 2017, 7, 46475.

(14) Zaidi, S. A.; Shin, J. H. Recent Developments in Nanostructure Based Electrochemical Glucose Sensors. Talanta 2016, 149, 30-42.

(15) Brownlee, B. J.; Marr, K. M.; Claussen, J. C.; Iverson, B. D. Improving Sensitivity of Electrochemical Sensors with Convective Transport in Free-standing, Carbon Nanotube Structures. Sens. Actuators, B 2017, 246, 20-28.

(16) Amatatongchai, M.; Sroysee, W.; Chairam, S.; Nacapricha, D. Amperometric Flow Injection Analysis of Glucose Using Immobilized Glucose Oxidase on Nano-Composite Carbon Nanotubes-Platinum Nanoparticles Carbon Paste Electrode. Talanta 2017, 166, 420-427.

(17) Dashty, M. A Quick Look at Biochemistry: Carbohydrate Metabolism. Clin. Biochem. 2013, 46, 1339-1352.

(18) IDF Diabetes Atlas, 8th ed.; International Diabetes Federation: Brussels, Belgium, 2017.

(19) Domingueti, C. P.; Dusse, L. M. S. A.; Carvalho, M. d. G.; de Sousa, L. P.; Gomes, K. B.; Fernandes, A. P. Diabetes Mellitus: The Linkage Between Oxidative Stress, Inflammation, Hypercoagulability and Vascular Complications. J. Diabetes Complicat. 2016, 30, 738745 .

(20) Klonoff, D. C.; Ahn, D.; Drincic, A. Continuous Glucose Monitoring: A Review of the Technology and Clinical Use. Diabetes Res. Clin. Pract. 2017, 133, 178-192.

(21) Viswanath, B.; Choi, C. S.; Lee, K.; Kim, S. Recent Trends in the Development of Diagnostic Tools for Diabetes Mellitus Using Patient Saliva. Trac. Trends Anal. Chem. 2017, 89, 60-67.

(22) Gupta, S.; Sandhu, S. V.; Bansal, H.; Sharma, D. Comparison of Salivary and Serum Glucose Levels in Diabetic Patients. J. Diabetes Sci. Technol. 2015, 9, 91-96.

(23) Zhao, C.-e.; Gai, P.; Song, R.; Chen, Y.; Zhang, J.; Zhu, J.-J. Nanostructured material-based biofuel cells: recent advances and future prospects. Chem. Soc. Rev. 2017, 46, 1545-1564.

(24) Gamella, M.; Koushanpour, A.; Katz, E. Biofuel cells Activation of micro- and macro-electronic devices. Bioelectrochemistry 2018, 119, 33-42.

(25) Cosnier, S.; Gross, A. J.; Le Goff, A.; Holzinger, M. Recent Advances on Enzymatic Glucose/Oxygen and Hydrogen/Oxygen Biofuel Cells: Achievements and Limitations. J. Power Sources 2016, $325,252-263$.

(26) Abreu, C.; Nedellec, Y.; Gross, A. J.; Ondel, O.; Buret, F.; Goff, A. L.; Holzinger, M.; Cosnier, S. Assembly and Stacking of Flowthrough Enzymatic Bioelectrodes for High Power Glucose Fuel Cells. ACS Appl. Mater. Interfaces 2017, 9, 23836-23842.
(27) Sassolas, A.; Blum, L. J.; Leca-Bouvier, B. D. Immobilization Strategies to Develop Enzymatic Biosensors. Biotechnol. Adv. 2012, 30, 489-511.

(28) Mross, S.; Pierrat, S.; Zimmermann, T.; Kraft, M. Microfluidic Enzymatic Biosensing Systems: A Review. Biosens. Bioelectron. 2015, 70, 376-391.

(29) Shi, J.; Claussen, J. C.; McLamore, E. S.; Ul Haque, A.; Jaroch, D.; Diggs, A. R.; Calvo-Marzal, P.; Rickus, J. L.; Marshall Porterfield, D. A Comparative Study of Enzyme Immobilization Strategies for Multi-Walled Carbon Nanotube Glucose Biosensors. Nanotechnology 2011, 22, 355502.

(30) Zhu, H.; Li, L.; Zhou, W.; Shao, Z.; Chen, X. Advances in Nonenzymatic Glucose Sensors Based on Metal Oxides. J. Mater. Chem. B 2016, 4, 7333-7349.

(31) Luo, Y.; Kong, F.-Y.; Li, C.; Shi, J.-J.; Lv, W.-X.; Wang, W. Onepot Preparation of Reduced Graphene Oxide-Carbon Nanotube Decorated with $\mathrm{Au}$ Nanoparticles Based on Protein for Nonenzymatic Electrochemical Sensing of Glucose. Sens. Actuators, B 2016, 234, 625-632.

(32) Zen, J.-M.; Lo, C.-W. A Glucose Sensor Made of an Enzymatic Clay-Modified Electrode and Methyl Viologen Mediator. Anal. Chem. 1996, 68, 2635-2640.

(33) Ghica, M. E.; Brett, C. M. A. A Glucose Biosensor Using Methyl Viologen Redox Mediator on Carbon Film Electrodes. Anal. Chim. Acta 2005, 532, 145-151.

(34) Watt, G. D. Kinetic Evaluation of the Viologen-Catalyzed Carbohydrate Oxidation Reaction for Fuel Cell Application. Renewable Energy 2014, 63, 370-375.

(35) Marr, K. M.; Chen, B.; Mootz, E. J.; Geder, J.; Pruessner, M.; Melde, B. J.; Vanfleet, R. R.; Medintz, I. L.; Iverson, B. D.; Claussen, J. C. High Aspect Ratio Carbon Nanotube Membranes Decorated with Pt Nanoparticle Urchins for Micro Underwater Vehicle Propulsion via H2O2 Decomposition. ACS Nano 2015, 9, 7791-7803.

(36) Chen, B.; Garland, N. T.; Geder, J.; Pruessner, M.; Mootz, E.; Cargill, A.; Leners, A.; Vokshi, G.; Davis, J.; Burns, W.; Daniele, M. A.; Kogot, J.; Medintz, I. L.; Claussen, J. C. Platinum Nanoparticle Decorated $\mathrm{SiO} 2$ Microfibers as Catalysts for Micro Unmanned Underwater Vehicle Propulsion. ACS Appl. Mater. Interfaces 2016, 8, 30941-30947.

(37) Claussen, J. C.; Daniele, M. A.; Geder, J.; Pruessner, M.; Mäkinen, A. J.; Melde, B. J.; Twigg, M.; Verbarg, J. M.; Medintz, I. L. Platinum-Paper Micromotors: An Urchin-Like Nanohybrid Catalyst for Green Monopropellant Bubble-Thrusters. ACS Appl. Mater. Interfaces 2014, 6, 17837-17847.

(38) Wang, X.; Kim, S. B.; Khang, D.; Kim, H.-H.; Kim, C.-J. Optimization and Characterization of Covalent Immobilization of Glucose Oxidase for Bioelectronic Devices. Biochem. Eng. J. 2016, 112, 20-31.

(39) Bockris, J. O.; Oldfield, L. F. The Oxidation-Reduction Reactions of Hydrogen Peroxide at Inert Metal Electrodes and Mercury Cathodes. Trans. Faraday Soc. 1955, 51, 249-259.

(40) Anderson, L.; Wittkopp, S. M.; Painter, C. J.; Liegel, J. J.; Schreiner, R.; Bell, J. A.; Shakhashiri, B. Z. What Is Happening When the Blue Bottle Bleaches: An Investigation of the Methylene BlueCatalyzed Air Oxidation of Glucose. J. Chem. Educ. 2012, 89, 14251431.

(41) De Wit, G.; Kieboom, A. P. G.; van Bekkum, H. Enolisation and Isomerisation of Monosaccharides in Aqueous, Alkaline Solution. Carbohydr. Res. 1979, 74, 157-175.

(42) Monk, P. M. S. The Viologens: Physicochemical Properties, Synthesis and Applications of the Salts of 4,4'-Bipyridine; Wiley: Chichester, NY, 1998.

(43) Ding, S.; Das, S. R.; Brownlee, B. J.; Parate, K.; Davis, T. M.; Stromberg, L. R.; Chan, E. K. L.; Katz, J.; Iverson, B. D.; Claussen, J. C. CIP2A Immunosensor Comprised of Vertically-aligned Carbon Nanotube Interdigitated Electrodes Towards Point-of-Care Oral Cancer Screening. Biosens. Bioelectron. 2018, 117, 68-74. 
(44) Sun, S.; Yang, D.; Zhang, G.; Sacher, E.; Dodelet, J.-P. Synthesis and Characterization of Platinum Nanowire-Carbon Nanotube Heterostructures. Chem. Mater. 2007, 19, 6376-6378.

(45) González-Gaitán, C.; Ruiz-Rosas, R.; Morallón, E.; CazorlaAmorós, D. Effects of the Surface Chemistry and Structure of Carbon Nanotubes on the Coating of Glucose Oxidase and Electrochemical Biosensors Performance. RSC Adv. 2017, 7, 26867-26878.

(46) Chen, C.; Xie, Q.; Yang, D.; Xiao, H.; Fu, Y.; Tan, Y.; Yao, S. Recent Advances in Electrochemical Glucose Biosensors: A Review. RSC Adv. 2013, 3, 4473-4491. 